\title{
Mechanisms of Nociceptive Signal Coding: Role of Slow Sodium Channels
}

\author{
E. V. Lopatina ${ }^{a, b}$, V. B. Plakhova ${ }^{a}$, T. N. Shelykh ${ }^{a}$, I. V. Rogachevsky ${ }^{a}$, V. A. Penniyaynen ${ }^{a}$, \\ V. A. Podzorova ${ }^{a}$, and B. V. Krylov ${ }^{a}$ \\ a Pavlov Institute of Physiology, Russian Academy of Sciences, nab. Makarova, 6, St. Petersburg, 199034Russia; \\ e-mail: krylov@infran.ru \\ ${ }^{b}$ Almazov Federal Center of Heart, Blood and Endocrynology, \\ ul. Akkuratova, St. Petersburg, 19734 Russia
}

DOI: $10.1134 / \mathrm{S} 1990747809030325$

Using whole-cell patch-clamp method, the rat DRG nociceptive neuron membrane was investigated. Extracellular ouabain applications lead to a decrease of the effective charge transfer in the activation gating system of the slow sodium channels $\left(\mathrm{TTX}_{\mathrm{r}}, \mathrm{Na}_{\mathrm{v}} 1.8\right)$. Ouabain concentration-effective charge transfer (doseresponse) dependence has U-like shape after extracellular ouabain application. Left branch of this dependence is monotonous in the range from $100 \mathrm{pM}$ to $1 \mu \mathrm{M}$ $\left(\mathrm{K}_{\mathrm{d}}=3 \mathrm{nM}\right)$. Quantum-chemical calculations have shown that the ouabain molecule could effectively form the chelate complex with free calcium ion. As a result, the equilibrium geometry of this complex changes and the probable consequence of this binding is the fact that this complex better fits the transducer site of the $\mathrm{Na}^{+}, \mathrm{K}^{+}$-ATPase. Besides, the chelate complex should specifically activate this transducer site due to the ionionic binding. Less specific free (without calcium) ouabain higher concentration binding takes place at the different $\mathrm{Na}^{+}, \mathrm{K}^{+}$-ATPase site that probably controls its pumping function. Heterogeneity of the ouabain binding sites could explain the U-like shape of the doseresponse function under investigation. The inflammatory pain test shows that injections of ouabain at low concentration (i.p., $0.3 \mathrm{mg} / \mathrm{kg}$ ) lead to pain relief. We hypothesize that physiological role of the endogenous ouabain results in the decrease of nociceptive signals. 